Sriwahyuni, Aldri FrinaldilBudaya Kerja Sadar Wista yang Responsif bagi Keselamatan Pengunjung (Studi Kolaborasi Pemerintah Kota Padang dengan Padang Baywatch di Kawasan Pantai Padang Kota Padang)

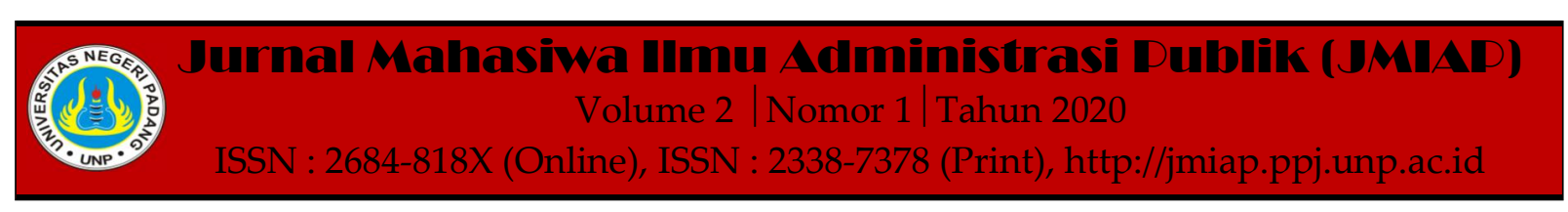

\title{
BUDAYA KERJA SADAR WISTA YANG RESPONSIF BAGI KESELAMATAN PENGUNJUNG (STUDI KOLABORASI PEMERINTAH KOTA PADANG DENGAN PADANG BAYWATCH DI KAWASAN PANTAI PADANG KOTA PADANG)
}

\author{
Sriwahyuni ${ }^{1(a)}$, Aldri Frinaldi ${ }^{2(b)}$ \\ ${ }^{1}$ Jurusan Ilmu Administrasi Negara, Universitas Negeri Padang \\ ${ }^{2}$ Jurusan Ilmu Administrasi Negara, Universitas Negeri Padang \\ a)siwahyuni08021997@gmail.com, ${ }^{b)}$ alfrinaldi@gmail.com
}

\begin{abstract}
Based on Law Number 10 of 2009 concerning Tourism, Article 24 Paragraph 1 Point (a) explains that one of the obligations of the government and regional governmenst is to provide tourism information, legal protection and the safety of tourist. To protect the safety of visitors who play on the coast the Padang City Government collaborates with Padang Baywatch, which is reflected in a responsive tourism-awere work culture. However, in reality there was a miss communication between the OPD involved with Padang Baywatch, the mean of safety whitch was minimal and not stand by the safety officer at the beach location. The purpose of study is to describe a work-aware tourism culture that was responsive to visitor safety (a collaborative study of the Padang City Government with Padang Baywatch in the Padang Beach Region, Padang City). This research is a qualitative research witch descriptive method. This study uses a model of work-aware tourism culture that is responsive to Aldri dan Khaidir, which was developed and modified by researchers into 3 indicators. The results of the study showed that a tourism-aware work culture that was responsive to the safety of vistors by the Padang City Government with Padang Baywatch was still not optimal, as evidence there were still many problems regarding tourism-awere work culture that was responsive to the Padang City Government's OPD Officials concerned, as well as Padang Baywatch Volunteers.
\end{abstract}

Keywords : Responsive Tourism Work Culture, Visitor Safety, Local Government, Padang Baywatch

Corresponding author. Email.siwahyuni08021997@gmail.com,alfrinaldi@gmail.com

How to cite this article. Sriwahyuni \& Frinaldi, A. (2020). Budaya Kerja Sadar Wista yang Responsif bagi Keselamatan Pengunjung (Studi Kolaborasi Pemerintah Kota Padang dengan Padang Baywatch di Kawasan Pantai Padang Kota Padang). Jurnal Mahasiwa Ilmu Administrasi Publik (JMIAP) Jurusan Ilmu Administrasi Negara Fakultas Ilmu Sosial Universitas Negeri Padang, Volume 2 (1), Hal. 138-124. http://jmiap.ppj.unp.ac.id

ISSN : 2684-818X (Online), ISSN : 2338-7378 (Print)

Copyright $(2020$. Published by Pusat Kajian-Pemberdayaan dan Pelayanan Masyarakat (PK-P2M) FIS UNP Padang 
Sriwahyuni, Aldri FrinaldilBudaya Kerja Sadar Wista yang Responsif bagi Keselamatan Pengunjung (Studi Kolaborasi Pemerintah Kota Padang dengan Padang Baywatch di Kawasan Pantai Padang Kota Padang)

\section{PENDAHULUAN}

Dewasa ini berwisata telah men-jadi life style suatu masyarakat, sehingga sektor kepariwisataan kini telah menjadi salah satu sumber perekonomian di du-nia yang menjanjikan. Karena jika dike-lola dengan baik dapat meningkatkan pendapatan, memperluas lapangan pe-kerjaan dan memperkenalkan budaya suatu negara. Pengembangan sektor pa-riwisata, kondisi yang responsif terha-dap kebutuhan pengunjung sangat pen-ting. Lingkungan pariwisata yang res-ponsif merupakan salah satu kepuasan pengunjung.

Destinasi Kawasan Pantai Padang Kota Padang terletak di Kecamatan Pa-dang Barat, Kota Padang, Sumatera Ba-rat. Dengan panjang pantai mencapai $4 \mathrm{KM}$ yang terdiri dari enam sektor pantai, yaitu (1) Pantai Muara yang terbentang dari Pintu Muara - Simpang Nipah; (2) Pantai Jalan Samudra yang terbentang dari Simpang Nipah - Hang Tuah; (3) Pantai Olo Ladang yang terbentang dari Simpang Hang Tuah Simpang Olo La-dang; (4) Pantai Purus yang terbentang dari Simpang Dif Olo
Ladang - Tugu IORA; (5) Pantai Cimpago yang ter-bentang dari Tugu IORAJembatan Pu-rus; dan (6) Pantai Muara Lasak yang terbentang dari Jembatan Purus - Fly O-ver di Belakang Hotel Pangeran Beach.

Pemerintah Kota Padang dalam pengembangan wisata Kawasan Pantai Padang telah melakukan sterilisasi bangunan liar, membangun berbagai infrastruktur seperti membangun taman, tugu IORA, Tugu Merpati Perdamaian, pelebaran jalan dan sebagainya. Akan tetapi pengembangunan tersebut belum mam-pu membuat pengunjung merasakan ko-ndisi pariwisata yang responsif bagi keselamatan pengunjung saat bermain di pantai. Karena setiap tahunnya terdapat pengunjung yang tenggelam akibat ter-seret ombak. Berdasarkan data yang di-rangkum dari BPBD Kota Padang dan Kantor Pencarian dan Pertolongan Kelas A Padang bahwa pada tahun 2014 - 2018 jumlah korban yang mengalami kecelakaan pantai mengalami fluktuasi, data tersebut dapat dilihat pada tabel be-rikut:

Tabel 1. Data Kecelakaan Pengunjung di Kawasan Pantai Padang

\begin{tabular}{cccc}
\hline No & Tahun & Jumlah Korban & Persentase \\
\hline 1 & 2014 & 6 Orang & $35,29 \%$ \\
2 & 2015 & 2 Orang & $11,76 \%$ \\
3 & 2016 & 1 Orang & $5,88 \%$ \\
4 & 2017 & 5 Orang & $29,41 \%$ \\
5 & 2018 & 3 Orang & $17,65 \%$
\end{tabular}

Sumber: Data BPBD Kota Padang dan Kantor Pencarian dan Pertolongan Kelas A Padang (2019)

Berdasarkan tabel di atas menun-jukkan bahwa dalam pengembangan wi-sata Kawasan Pantai Padang keselama-tan pengunjung sangat penting untuk di perhatikan. Berdasarkan (Undang-undang Republik Indonesia Nomor 10 Tahun 2009 tentang Kepariwisataan, n.d.) pada pasal 23 ayat 1 poin (a) men-jelaskan bahwa salah satu kewajiban pe-merintah dan pemerintah daerah yaitu menyediakan informasi kepariwisataan, perlindungan hukum serta keamanan dan keselamatan wisatawan. Sehingga untuk mewujudkan pariwisata yang res-ponsif bagi keselamatan pengunjung ya-ng bermain di pantai dibutuhkan kola-borasi antara pemerintah Kota Padang dengan masyarakat.

Dalam kegiatan pembangunan kepariwisataan dibutuhkan peran seluruh pemangku kepentingan seperti pe-merintah, swasta dan masyarakat untuk saling kolaborasi dan besinergi dalam mencapai 
Sriwahyuni, Aldri FrinaldilBudaya Kerja Sadar Wista yang Responsif bagi Keselamatan Pengunjung (Studi Kolaborasi Pemerintah Kota Padang dengan Padang Baywatch di Kawasan Pantai Padang Kota Padang)

sasaran pembangunan yang diharapkan (Rahim, 2012). Kemudian, dalam membangun, mengembangkan atau meningkatkan kepariwisataan meli-batkan banyak komponen, termasuk Or-ganisasi Perangkat Daerah (OPD) terkait (Frinaldi \& Khaidir, 2018). Untuk mewujudkan pariwisata yang responsif bagi keselamatan pengunjung, Pemeri-ntah Kota Padang melibatkan Dinas Pa-riwisata dan Kebudayaan Kota Padang, Dinas Kesehatan Kota Padang, Satpol PP Kota Padang dan BPBD Kota Pa-dang untuk berkolaborasi dengan Pada-ng Baywatch, yang merupakan masyara-kat sekitar pantai yang menyadari peran dan tanggung jawabnya sebagai tuan ru-mah yang baik bagi pengunjung untuk mewujudkan lingkungan dan suasana yang kondusif untuk menjaga keselama-tan pengunjung, yang tercermin dalam budaya kerja sadar wisata yang respon-sif bagi keselamatan pengunjung.

Akan tetapi, kenyataannya masih ditemukan permasalahan, seperti hubungan kolaborasi antara Pemerintah Kota Padang dengan Padang Baywatch belum berjalan dengan baik, masih terjadi miss communication akibat dari banyaknya OPD yang berperan dalam pengemba-ngan wisata Kawasan Pantai Padang. Sarana dan prasarana yang dapat me-ngoptimalkan pariwisata yang responsif bagi keselamatan pengunjung masih ku-rang, seperti belum adanya kendaraan BPBD, belum adanya atribut batas aman bermain dan pelampung serta tidak ada-nya peralatan lainnya yang stand by di-lokasi pantai.

Berdasarkan hasil observasi pe-neliti pada 24 Desember 2018 tidak me-nemukan keberadaan Padang Baywatch di sekitar pantai dan masih banyaknya pengunjung yang tidak mengetahui ke-beradaan Padang Baywatch. Lalu pene-liti juga tidak menemukan adanya petu-gas dari pemerintah Kota Padang mela-kukan pengawasan kepada pengunjung yang bermain di Kawasan Pantai Pada-ng. Kemudian, berdasarkan wawancara dengan Ketua Padang Bawatch 30 Janu-ari 2019 menyebutkan, sebagai relawan penjaga pantai, jumlah anggota yang aktif sangat sedikit, lalu minimnya sara-na informasi dan komunikasi keselama-tan serta peralatan keselamatan yang ti-dak memadai yang dimiliki Padang Bay-watch.

Berdasarkan permasalahan terse-but peneliti tertarik untuk meneliti buda-ya kerja sadar wisata yang responsif ba-gi keselamatan pengunjung (kolaborasi Pemerintah Kota Padang dengan Padang Baywatch di Kawasan Pantai, Padang Kota Padang)

\section{TINJAUAN PUSTAKA}

\section{Budaya Kerja Sadar Wisata yang Responsif}

Budaya kerja menurut Aldri (Frinaldi, 2017; Frinaldi \& Embi, 2014) mengungkapkan bahwa budaya kerja adalah filsafat yang didasarkan pada pendapat hidup sebagai nilai ke dalam sifat, kebiasaan dan kekuatan pendo-rong, tertanam dalam kelompok masya-rakat atau organisasi yang tercermin da-lam sikap kemudian perilaku, keperca-yaan, cita-cita, pandangan dan tindakan.

Budaya kerja sadar wisata menurut Aldri dan Khaidir $(2017,2018)$ adalah nilai yang menjadi cara hidup ke-mudian menjadi suatu kebiasaan dan cerminan dalam sikap, perilaku dan ke-pedulian dalam interaksi sosial dalam upaya mewujudkan pertumbuhan dan pembangunan pariwisata, yang dapat mendorong pertumbuhan dan kesejahte-raan kehidupan sosial ekonomi masya-rakat. Kemudian berkaitan dengan ka-rakteristik budaya kerja sadar wisata menurut Aldri, Khaidir dan Rahayu (2019) bahwa budaya kerja merupakan konsep yang dapat memperluas pandangan pariwisata, tidak hanya mempertimbangkan dampak ekonomi jangka pendek, tetapi dengan mengembangkan budaya kerja sadar wisata dalam perspektif pariwisata dapat mengembangkan dan meningkatkan pariwisata berkelanjutan yang sejalan dengan pertumbuhan ekonomi yang popular (Frinaldi, Khaidir, \& Yulista R, 2019). Hal 
Sriwahyuni, Aldri FrinaldilBudaya Kerja Sadar Wista yang Responsif bagi Keselamatan Pengunjung (Studi Kolaborasi Pemerintah Kota Padang dengan Padang Baywatch di Kawasan Pantai Padang Kota Padang)

tersebut dapat menjadi upaya menanggapi harapan pengunjung sehi-ngga mereka mendapatkan kesan penga-laman yang dapat meningkatkan kua-litas, kepuasan dan kebahagiaan. Buda-ya kerja sadar wisata dapat menjadi ben-tuk karakteristik mental yang berisikan makna harapan, nilai-nilai dan pengala-man yang berguna untuk meningkatkan kemampuan dan kapasitas sumber daya manusia dan sumber daya lainnya.

Sedangkan dimensi budaya kerja sadar wisata menurut Aldri dan Khaidir (2017, 2018) serta Aldri, Khaidir dan Rahayu (2019) adalah sebagai berikut:

1) Aman, adalah suatu kondisi lingkungan di destinasi pariwisata atau daerah tujuan wisata yang member-kan rasa tenang, bebas dari rasa ta-kut dan kecemasan bagi wisatawan untuk bepergian kedaerah tujuan wisata tersebut.

2) Tertib, adalah suatu kondisi linku-ngan dan pelayanan di destinasi pa-riwisata atau daerah tujuan wisata yang mencerminkan disiplin tinggi serta kualitas fisik dan layanan yang konsisten dan teratur serta efesien sehingga dapat memberikan rasa nyaman dan kepastian bagi wisata-wan.

3) Bersih, adalah suatu kondisi lingkungan serta kualitas produk dan pelayanan di destinasi pariwisata atau daerah tujuan wisata yang mencerminkan keadaan yang sehat/higienis, sehingga memberikan rasa nyaman dan senang bagi wisatawan.

4) Sejuk, adalah suatu kondisi ling-kungan di destinasi pariwisata atau daerah tujuan wisata yang mencer-minkan keadaan yang sejuk dan te-duh yang memberikan perasaan nyaman dan betah bagi wisatawan.

5) Indah, adalah suatu kondisi di lingkungan destinasi pariwisata atau daerah tujuan wisata yang men-cerminkan yang indah dan menarik yang akan memberikan rasa kagum dan kesan yang mendalam bagi wi-satawan sehingga mewujudkan po-tensi kunjungan ulang dan mendo-rong promosi kepasar pariwisata ya-ng lebih luas.

6) Ramah, adalah suatu kondisi lingkungan yang bersumber dari sikap masyarakat di destinasi pariwisata atau daerah tujuan wisata yang mencerminkan suasana yang akrab, terbuka dan menerima yang tinggi yang akan memberikan perasaan nyaman perasaan diterima dan be-tah bagi wisatawan.

7) Kenangan, adalah suatu bentuk pengalaman yang tidak terlupakan di destinasi wisata yang akan memberikan rasa senang dan kenangan indah bagi wisatawan.

8) Sopan, adalah suatu kondisi di destinasi wisata yang berasal dari sikap masyarakat yang mencerminkan tingkah laku dan tutur kata yang mampu menimbulkan suasa sanang dan bahagia bagi wisatawan.

9) Santun, adalah suatu kondisi di destinasi wisata yang mencerminkan sikap ketenangan dan kesabaran se-hingga mempunyai kesan adanya penghargaan dan penghormatan ter-hadap orang lain.

10) Responsif, merupakan suatu kondisi di destinasi wisata yang mencer-minkan sikap cepat dalam member-kan respons kepada wisatawan yang berkunjung.

Sehubungan dengan penelitian yang di kembangkan peneliti, berkaitan dengan responsif. Menurut Aldri dan Khaidir (2018) responsif di dalam bu-daya kerja sadar wisata adalah mem-punyai kesadaran dan kepekaan dalam menanggapi situasi dan kondisi dalam usaha memahami orang lain. Dari defe-nisi dan karakteristik responsif didalam budaya kerja sadar wisata di atas maka peneliti mengembangkan dan memodi-fikasi bahwa situasi dan kondisi yang di-maksud adalah situasi saat pengunjung bermain di pantai dan kondisi yang di-maksud adalah keadaan lingkungan ya-ng dapat mengancam keselamatan pe- 
Sriwahyuni, Aldri FrinaldilBudaya Kerja Sadar Wista yang Responsif bagi Keselamatan Pengunjung (Studi Kolaborasi Pemerintah Kota Padang dengan Padang Baywatch di Kawasan Pantai Padang Kota Padang)

ngunjung. Kemudian usaha untuk memahami orang lain dapat dipahami se-bagai kemampuan untuk mengetahui dan merasakan apa yang pengunjung ra-sakan saat bermain di pantai. Memiliki kesadaran dimaknai sebagai kemampuan mempersepsikan, berinteraksi dan berkomunikasi dengan pengunjung se-cara terpadu. Selanjutnya memiliki ke-pekaan dapat dipahami sebagai kesang-gupan untuk bereaksi terhadap suatu ke-adaan dan tidak lalai terkait tugasnya menjamin keselamatan pengunjung. Se-hingga dapat disimpulkan bahwa indi-kator responsif didalam budaya kerja sa-dar wisata berdasarkan modifikasi dari pendapat Aldri dan Khaidir (2018) ada-lah (1) kemampuan untuk mengetahui dan merasakan apa yang pengunjung ra-sakan saat bermain di pantai; (2) ke-mampuan mempersepsikan, berinteraksi dan berkomunikasi dengan pengunjung secara terpadu; kesanggupan untuk bereaksi terhadap suatu keadaan dan ti-dak lalai terkait tugasnya menjamin ke-selamatan pengunjung.

\section{Keselamatan Pengunjung}

Menurut Mathis dan Jackson (dalam Harini \& Putra, 2017) mendefi-nisikan keselamatan dengan merujuk ke-pada perlindungan kesejahteraan fisik seseorang terhadap cidera yang ber-kaitan dengan apa yang dikerjakannya. Keselamatan pengunjung adalah segala bentuk perlindungan terhadap pengun-jung dari segala bentuk resiko, kecela-kaan dan kerugian yang timbul dari ben-cana alam maupun bencana akibat peran manusia. Pengunjung harus diberikan perlindungan dalam setiap aktivitas ya-ng dilakukan di tempat wisata dari awal kedatangan hingga kepulangan dari tem-pat wisata (Paramitha, 2012). Untuk me-cegah terjadinya resiko yang ditimbul-kan dari kegiatan berwisata di pantai, dibutuhkan saran keselamatan seperti Lifeguard atau penjaga pantai, peralatan informasi dan komunikasi, pelampung, peralatan penyelamatan aktivitas air, bendera keselamatan dan sarana penye-lamatan diri (Australian Coastal Public Safety Guidelines dalam (Paramitha, 2012).

\section{Pemerintah Derah}

Negara Kesatuan Republik In-donesia dibagi atas daerah provinsi dan daerah provinsi di bagi menjadi daerah kabupaten/kota. Berdasarkan ("Undangundang Republik Indonesia Nomor 23 Tahun 2014 tentang Pemerintah Dae-rah," n.d.) pada Pasal 1 Ayat (2) menye-butkan bahwa pemerintah daerah adalah penyelenggaraan urusan pemerintah o-leh pemerintah daerah dan dewan per-wakilan daerah menurut asas otonomi dan tugas pembantuan dengan prinsip otonomi yang seluas-luasnya dalam sis-tem dan prinsip Negara Kesatuan Re-publik Indonesia sebagaimana dimaksud dalam UndangUndang Dasar Negara Republik Indonesia. Kemudian pada pa-sal 1 ayat (3) menjelaskan pemerintah daerah adalah kepala daerah sebagai un-sur penyelenggara pemerintahan daerah yang memimpin pelaksanaan urusan pe-merintahan yang menjadi kewenangan daerah otonom.

\section{Padang Baywatch}

Padang Baywatch secara bahasa tersusun dari dua kata yaitu Padang dan Baywatch. Kata Padang merupakan na-ma kota dan menjadi Ibu Kota Provinsi Sumatera Barat yang terletak di Pulau Sumatera. Kemudian Kata Baywatch be-rasal dari bahasa inggris, yang terbagi dua suku kata, yaitu kata "bay" yang ar-tinya teluk dan "watch" artinya menonton, mengamati, memperhatikan dan menjaga (Echols \& Shadily, 2012). Sehingga jika di gabungkan Baywatch adalah penjaga teluk (pantai). Jadi Padang Baywatch adalah penjaga pantai yang ada di Kota Padang.

Padang Baywatch adalah organi-sasi masyarakat bersifatnya relawan se-bagai penjaga pantai yang memiliki ke-mampuan search and rescue dan ber-peran sebagai penjaga pantai. Kemudian Padang Baywatch bermitra dengan Ba-sarnas Kota 
Sriwahyuni, Aldri FrinaldilBudaya Kerja Sadar Wista yang Responsif bagi Keselamatan Pengunjung (Studi Kolaborasi Pemerintah Kota Padang dengan Padang Baywatch di Kawasan Pantai Padang Kota Padang)

Padang sebagai Potensi SAR yang bertanggung jawab kepada Kepala Kantor SAR Padang.

\section{METODE PENELITIAN}

Penelitian ini menggunakan me-tode kualitatif deskriptif. Penelitian ini dilakukan di Kawasan Pantai Padang Kota Padang, pada OPD Pemerintah Kota Padang seperti Dinas Pariwisata dan Kebudayaan Kota Padang, Dinas Kesehatan Kota Padang, Dinas Sosial Kota Padang, Satpol PP Kota Padang dan Badan Penanggulangan Bencana Daerah Kota Padang serta Padang Bay-watch. Informan penelitian ditentukan dengan cara purposive sampling dan insidental sampling. Sehingga, yang menjadi informan dalam penelitian ini adalah Kepala Seksi Usaha dan Industri Pariwisata, Kepala Seksi Pelayanan Ke-sehatan Primer dan Tradisional, Kepala Seksi Perlindungan Perlindungan Sosial Korban Bencana Alam, Koordinator Pe-nyidik Satpol PP Kota Padang, Kepala Seksi Kedaruratan, Ketua Padang Bay-watch dan Pengunjung yang bermain di Kawasan Pantai Padang sebanyak tiga belas orang. Data yang digunakan dalam penelitian ini yaitu data primer dan skunder. Pengumpulan data dilakukan dengan cara wawancara, observasi dan studi dokumentasi dengan uji keabsahan data menggunakan triangulasi sumber dan triangulasi metoda. Sedangkan un-tuk teknik analisis data dilakukan dengan cara reduksi data, penyediaan data dan penarikan kesimpulan.

\section{HASIL DAN PEMBAHASAN}

Dalam penelitian ini peneliti menggunakan teori budaya kerja sadar wi-sata yang memodifikasi teori dari Aldri dan Khaidir tentang responsif dalam kharakteristik budaya kerja sadar wisata. Teori tersebut dimodifikasi dan dikembangkan berdasarkan kebutuhan peneli-tian dan karakteristik responsif di dalam budaya kerja sadar wisata yang dimo-difisikasi dapat menjelaskan secara komprehensif tentang budaya kerja sa-dar wisata yang responsif bagi kese-lamatan pengunjung (studi kolaborasi Pemerintah Kota Padang dengan Padang Baywatch di Kawasan Pantai Padang). Adapun karakteristik ataupun indikator didalam budaya kerja sadar wisata yang responsif adalah kemampuan menge-tahui dan merasakan apa yang pengun-jung rasakan, kemampuan memper-sepsikan, berinteraksi dan berkomuni-kasi secara terpadu dan kesanggupan un-tuk bereaksi terhadap suatu keadaan dan tidak lalai terkait tugasnya menjamin ke-selamatan pengunjung.

\section{Kemampuan Mengetahui dan Merasakan Apa yang Pengun-jung Rasakan saat Bermain di Pantai}

Untuk menentukan bagaimana kemampuan Pemerintah Kota Padang bersama Padang Baywatch, mengetahui dan merasakan apa yang pengunjung ra-sakan saat bermain di pantai sudah baik atau belum dapat dilihat dari kutipan pendapat A (Koordinator Penyidik, Satpol PP Kota Padang) mengung-kapkan: “...Satpol PP ini kan ada BKO dengan Pariwisata, yang rutin patroli di setiap pantai sepanjang Muara Lasak dan Cimpago, Satpol PP bukan teknis penyelamatan, sehingga kami pun pat-roli ya begitu saja." (Wawancara 13 Mei 2019). Kemuidan, EP (Kasi Usaha dan Industri Pariwisata) mengungkapkan:

“...belum ada petugas khusus yang bertugas menjaga pantai, sehingga kami bermitra dengan Padang Baywatch yang memiliki kemampuan water rescue. Untuk asuransi pengunjung Pemko tidak memberikan. Pertanggung jawaban Pemko terhadap keselamatan, ya dari fasilitas mungkin, adanya himbauan, ada papan peringatan. Untuk acuan atau pedoman dalam penetapan sarana keselamatan, Dinas Pariwisata tidak sampai kesitu” (wawancara 14 Mei 2019).

Begitu pula SH (Seksi Kedaruratan, BPBD Kota Padang) mengungkapkan: 
Sriwahyuni, Aldri FrinaldilBudaya Kerja Sadar Wista yang Responsif bagi Keselamatan Pengunjung (Studi Kolaborasi Pemerintah Kota Padang dengan Padang Baywatch di Kawasan Pantai Padang Kota Padang)

“...Dari BPDB melakukan pengamanan dan patroli pada hari-hari tertentu saja, seperti hari libur baliamu atau lebaran dengan perlengkapan life jacket, pelampung, ring buoy dan perahu karet lengkap dengan mesin. Kegiatan itu kami bekerja sama dengan Padang Bawyatch melalui pembagian lokasi tugas. Untuk menara pengawas ada 1 di Pantai cimpago, di bangun di pusat keramain" (wawancara 14 Mei 2019). Kemudian, DA (selaku seksi kesehatan Primer dan Tradisional) mengungkapkan: “...Kontribusi Dinkes menyediakan tim-tim kesehatan pada tiap pengunjung rame, Sabtu sore jam 4-9 malam, dan Minggu dari jam 10 pagi dan sore dari jam 4-9 malam" (wawancara 28 Mei 2019). Lalu SH (Ketua Padang Baywatch) mengungkapkan: “...Kami bekerja sama dengan Pemko saat hari PAM libur balimau, lebaran, natal dan tahun baru. Perlengkapan kami saat bertugas dilengkapi dengan life jacket 12 buah dan perahu karet lengkap dengan mesin yang di pinjamkan Basarnas" (wawan-cara 10 Mei 2019).

Pengakuan dari beberapa peng-unjung, selama mereka bermain tidak selalu petugas atau pun relawan me-ngawasi pengunjung, bahkan ada yang mengungkapkan selama bermain di pan-tai tidak melihat petugas dan relawan. Lalu, masih banyak pengunjung yang ti-dak mengetahui adanya relawan Padang Baywatch, pengunjung merasa sarana keselamatan di Kawasan Pantai Padang masih sangat minim sekali. (Hasil wa-wancara dengan M Arobbi, Hilma, Aldi dan Haris pada 8 Juni 2019 dan Faisal, Baron, Yanti, dan Tabrani pada 9 Juni 2019). Kemudian hasil observasi yang dilakukan peneliti pada setiap hari minggu itu tidak menemukan petugas maupun relawan yang menjaga pantai, kemudian tanggal 8-9 Juni 2019 mene-mukan bahwa patroli mengawasi peng-unjung hanya dilakukan oleh Padang Baywatch melalui darat dan laut dengan menggunakan perahu karet mulai dari Simpang Nipah-Pantai Muara Lasak. Padang baywatch tidak selalu memakai baju Padang Baywatch yang bewarna orange, Safety mereka hanya life jacket, mereka juga terjun kelaut untuk menjadi pembatas aman berenang bagi pengun-jung.

Dari temuan diatas, dapat dipa-hami kemampuan Pemerintah Kota Pa-dang yang kolaborasi dengan Padang Baywatch untuk memahami dan merasakan pengunjung masih kurang baik. Menurut Aldri dan Khaidir (2018) karakteristik dalam responsif salah sa-tunya adalah usaha memahami orang la-in dalam berbagai situasi dan kondisi yang kemudian, dapat diukur dengan kemampuan mengetahui dan merasakan apa yang pengunjung rasakan. Kemam-puan yang baik untuk mengetahui dan merasakan apa yang pengunjung rasakan saat bermain dipantai, melalui seja-uh mana kesanggupan Pemerintah Kota Padang yang berkolaborasi dengan Pa-dang Baywatch mengetahui (segala se-suatu yang dapat mengancam keselama-tan pengunjung) dengan menyediakan sarana keselamatan pengunjung dari ba-haya resiko saat bermain air, ombak, be-renang, bermain pasir, memancing atau hanya sekedar melihat pemandangan. Paramitha (2012) menyebutkan resiko bermain di pantai seperti memancing memiliki resiko terjatuh kelaut sehingga dibutuhkan peralatan penyela-matan di-ri; berenang di pantai memiliki resiko tenggelam, tersambar petir, serangan he-wan laut, dan sengatan ubur-ubur, se-hingga di butuhkan peralatan penye-lamatan, sarana informasi dan peringa-tan serta penjaga pantai/ lifeguarad; ber-jemur, bermain pasir dan piknik memi-liki resiko terbakar matahari, dehidrasi, pasir masuk kemata, luka akibat benda tajam atau sengatan hewan sehinggga di perlukan peralatan medis.

Akan tetapi, hingga saat ini pe-merintah tidak memiliki acuan yang je-las tentang keselamatan pengunjung, ti-dak memahami apa yang menjadi resiko disetiap aktivitas pengunjung yang ber-main di pantai. Ini 
Sriwahyuni, Aldri FrinaldilBudaya Kerja Sadar Wista yang Responsif bagi Keselamatan Pengunjung (Studi Kolaborasi Pemerintah Kota Padang dengan Padang Baywatch di Kawasan Pantai Padang Kota Padang)

dapat dilihat dengan minimnya sarana keselamatan yang ada di lokasi pantai, hanya ada 1 papan him-bauan larangan berenang jika cuaca bu-ruk dan 1 bangunan tower pe-ngawas yang merangkap sebagai kantor pusat la-yanan terpadu yang terletak di Pantai Cimpago tepatnya LPC (Lapau Panjang Cimpago), tidak adanya petugas kese-lamatan di setiap hari, sebab penjagaan yang dilakukan hanya pada event-event tertentu seperti hari libur keagamaan dengan mengerahkah petugas dari Dinas Pariwisata, petugas P3K (Petugas Per-tolongan Pertama Pada Kecelakaan) dari Dinas Kesehatan, petugas dari BPBD Kota Padang dan Satpol PP BKO (Sa-tuan Polisi Pamong Praja Bawah Kenda-li Operasi) Pariwisata yang akan berko-laborasi dengan Padang Baywatch. Mes-ki demikian, tidak semua lokasi pantai mendapat penjagaan, kemudian petugas dari pemerintah hanya terfokus pada Pantai Cimpago. Sedangkan untuk me-lakukan patroli hanya dilakukan oleh Padang Baywatch, minimnya anggota serta perlengkapan personil menyebab-kan tidak semua titik pantai mendapat-kan penjagaan dan banyaknya pengun-jung yang tidak mengetahui adanya Pa-dang Baywatch sebagai relawan penjaga pantai.

\section{Kemampuan Mempersepsikan Berinteraksi dan Berkomuni-kasi secara Terpadu}

Untuk mengetahui kemampuan

Pemerintah Kota Padang dengan Padang Baywatch dalam mempersepsikan, berinteraksi dan berkomunikasi secara ter-padu telah baik atau belum, dapat dilihat dari kutipan pendapat EP (Kasi Usaha dan Industri Pariwisata) mengungkap-kan:

"Pada saat kondisi cuaca buruk relawan akan melakukan penyisiran pantai baik lewat laut dan darat. Himbauan dilakukan orang perorang menggunakan bahasa Indonesia dan Minang sesuai sikon saja" (Wawancara 14 Mei 2019), kemudian SH (Ketua Padang Baywatch) juga mengungkapkan: " $\mathrm{Ka}$ - mi mengetahui lingkungan disana kayak cuaca, tinggi ombak biasanya secara otodidak dan bantuan BMKG dan relawan lainnya. Kalau tidak ada PAM kami tidak bergerak, jika ada PAM kami mensosialisasikan kepada pengunjung, jika ingin bermain kami kawal, kami juga menghimbau kepada orang tua pengunjung jika cuaca buruk atau sudah magrib untuk membawa anaknya menjahui pantai" (Wawancara pada 10 Mei 2019).

Berdasarkan hasil observasi bahwasannya yang melakukan interaksi langsung kepada pengunjung adalah Pa-dang Baywatch dan tower pengawas ter-letak agak jauh dari bibir pantai, jika pengunjung padat, informasi dari Tower Pengawas LPC tidak akan jelas sampai kepengunjung. Kemudian, pengakuan beberapa pengunjung menjelaskan bah-wa, relawan Padang Baywatch akan memberikan himbauan jika cuaca buruk dan jika cuaca tidak buruk mereka membiarkan pengunjung bermain di pantai. Akan tetapi beberapa pengunjung tidak mendapatkan himbauan dari petuagas pemerintah atau pun relawan. Lalu, ada juga pengunjung yang mengeluhkan su-litnya memahami bahasa yang diguna-kan relawan Padang Baywatch. (Hasil Observasi pada 8-9 Juni 2019 dan hasil wawancara bersama Aeis, Darni, M Arobi pada 8 Juni 2019, serta Tabrani, Martian, Neza pada 9 Juni 2019).

Dari temuan di atas dapat di-pahami Petugas dari Pemerintah Kota Padang bersama relawan Padang Bay-watch dalam mempersepsikan keadaan lingkungan dan cuaca sudah cukup baik. Akan tetapi, untuk berinteraksi dan ber-komunikasi belum baik dan terpadu. Menurut Aldri dan Khaidir (2018), ka-rakteristik dalam responsif salah satunya adalah mewujudkan kesadaran dalam berbagai situasi dan kondisi. Dapat diu-kur dengan kemampuan mempersepsikan, berinterasksi dan berkomunikasi secara terpadu. Dengan melihat kemam- 
Sriwahyuni, Aldri FrinaldilBudaya Kerja Sadar Wista yang Responsif bagi Keselamatan Pengunjung (Studi Kolaborasi Pemerintah Kota Padang dengan Padang Baywatch di Kawasan Pantai Padang Kota Padang)

puan Pemerintah Kota Padang bersama Padang Baywatch dalam mempersepsi-kan keadaan lingkungan maupun kea-dan pengunjung yang dapat membaha-yakan keselamatan saat bermain di pan-tai kemudian dapat berinteraksi dan berkomunikasi memberikan informasi tersebut kepada pengunjung secara baik dan terpadu.

Pada saat bertugas, keadaan ling-kungan dapat mereka pantau secara la-ngsung dan kemampuan otodidak yang dimiliki Padang Baywatch dalam mem-perdiksi cuaca dan di dukung perkiraan cuaca dari Badan Meteologi Klimatologi dan Geofisika. Akan tetapi, meski dalam mempersepsikan keadaan lingkungan saat bertugas sudah cukup baik, petugas pemerintah tidak selalu langsung berin-teraksi dengan pengunjung untuk mem-berikan informasi. Karena masih banyak pengunjung di Kawasan Pantai Padang yang tidak mendapatkan informasi situ-asi cuaca dan lingkungan terkini. Sebab dalam hal ini, yang berinteraksi lang-sung untuk memberikan informasi ha-nya relawan Padang Baywatch, dengan secara perorangan kepada orang tua dari anak-anak yang bermain di pantai. se-dangkan petugas pemerintah memalui Dinas Pariwisata ataupun Petugas lain-nya memberikan informasi melalui pe-ngeras suara yang berpusat di Tower Pe-ngawas LPC. Tidak semua pengunjung memahami apa yang diinformasikan da-ri relawan Padang Baywatch maupun Petugas Pemerintah, yang disebabkan dialek yang digunakan relawan Padang Baywatch adalah Indonesia campur Mi-nang menyulitkan pengunjung, khusus-nya pengunjung luar daerah untuk me-mahaminya. Lalu pusat informasi him-bauan yang jaraknya cukup jauh dari bi-bir pantai dan padatnya pengunjung menjadi penyebab tidak tersampaikan-nya isi pesan tersebut. Akibatnya masih banyak pengunjung yang masih asik bermain di pantai meski cuaca buruk.

\section{Kesanggupan untuk Bereaksi terhadap suatu Keadaan dan Tidak Lalai terkait Tugasnya Menjamin Keselamatan Pe- ngunjung}

Untuk melihat keseanggupan Pemerintah Kota Padang dengan Padang Baywatch, bereaksi terhadap suatu keadaan dan tidak lalai terkait tugasnya da-pat dilihat dari kutipan pendapat SH (Ketua Padang Baywatch) yang meng-ungkapkan:

“... Pada saat PAM, jika pengunjung mengalami kecelakaan kami langsung mengejar, kalau terseretnya didepan mata, sambil anggota lain ber-kordinasi dengan BPBD dan Basarnas. Jika dihari biasa kami hanya di posko, jadi kalau ada yang kecelakaan dengan bantuan nelayan, mereka akan mengu-bungi kami, dan kami yang akan mem-berikan pertolongan pertama dengan terus berkoordinasi dengan Basarnas." (wawancara 14 Mei 2019).

DA (Kasi Kesehatan Primer dan Tradisional) juga mengungkapkan:

"...saat terjadi kecela-kaan akan dievakuasi oleh Padang Bay-watch dan $B P B D$ kemudian pengunjung dibawa menggunakan tandu milik $B P-B D$ biasanya ke posko P3K untuk dibe-rikan pertolongan pertama, jika kondisi semakin serius akan di rujuk ke $M$ Djamil" (Wawancara 28 Mei 2019).

Berdasarkan hasil observasi pada 24 Desember 2018 dan tangal 8-9 Juni 2019 bahwa posko kesehatan dan kese-lamatan itu hanya berada di Pantai Cim-pago, hanya Posko Padang Baywatch yang berada di Pantai Jl Samudra, di Kawasan Pantai Padang tidak memiliki call amergency kemudian 6 sektor pantai yang ada hanya memiliki papan informasi dan himbuan. Kemudian pera-latan yang dimiliki Padang Baywatch kurang terjaga dengan baik, seperti perahu di biarkan diletakkan di pinggir pantai tampa alas penutup.

Dari temuan di atas dapat dipa-hami bahwa reaksi Pemerintah Kota Pa-dang 
Sriwahyuni, Aldri FrinaldilBudaya Kerja Sadar Wista yang Responsif bagi Keselamatan Pengunjung (Studi Kolaborasi Pemerintah Kota Padang dengan Padang Baywatch di Kawasan Pantai Padang Kota Padang)

dengan Padang Baywatch pada su-atu keadaan belum dapat sepenuhnya di katakan baik, lalu masih lalainya Pemerintah Kota Padang dan Padang Bay-watch dalam menjalankan tugasnya me-njamin keselamatan pengunjung. Menu-rut Aldri dan Khaidir (2018) karakte-ristik dalam responsif salah satunya ada-lah peka terhadap situasi dan kondisi. Lalu dapat diukur dengan kesanggupan untuk bereaksi terhadap suatu keadaan dan tidak lalai terkait tugasnya men-jamin keselamatan pengunjung. Hal ter-sebut dapat dilihat dengan kemampuan Pemerintah Kota Padang dengan Padang Baywatch bereaksi dengan baik dan ce-pat terhadap pengunjung yang menga-lami musibah atau kecelakaan saat ber-main di pantai. kemudian tidak lalai ter-hadap tugasnya dalam menjaga kese-lamatan pengunjung.

Kenyataannya, reaksi Pemerin-tah Kota Padang bersama Padang Baywatch saat berkolaborasi menjaga keselamatan pengunjung pada event-event tertentu, sudah cukup baik dalam memberikan pertolongan pengunjung yang mengalami kecelakaan, seperti te-nggelam akibat terseret ombak saat ber-main. Jika kecelakaan terjadi di pantai yang dijaga oleh petugas pemerintah dan relawan Padang Baywatch maka akan segara di evakuasi oleh Padang Bay-watch dengan cara, jika pengunjung ma-sih terlihat maka akan mengejar dan menarik pengunjung kedaratan, kemudi-an BPBD akan membantu dengan segera membawa peralatan keselamatan seperti tandu dari Posko BPDB, kemudian pe-ngunjung dibawa ke Posko Tim P3K untuk diberikan pertolongan pertama. Lalu jika pengunjung kritis akan di ru-juk kerumah sakit terdekat dengan me-nggunakan Mobil Ambulance Keliling milik Dinas Kesehatan.

Akan tetapi jika pengunjung ya-ng mengalami kecelakaan di luar penga-wasan petugas dan relawan makan eva-kuasi akan lambat dilakukan. Begitu pu-la pada saat hari diluar event-event ter-tentu maka evakuasi akan jauh lebih lambat, karena relawan tidak berada di pantai hanya berada di Posko yang ter-letak di Pantai Jalan Samudra dan pe-tugas pemerintah seperti BPBD dan Tim P3K juga tidak berada di Kawasan Pantai Padang.

Pemerintah Kota Padang juga masih lalai terhadap tugas sebagai unsur pemerintah yang memiliki kewajiban menjaga keselamatan pengunjung, sebab masih minimnya sarana keselamatan, ti-dak adanya petugas dari pemerintah yang melakukan patroli untuk menjaga keselamatan pengunjung yang bermain, lalu tidak adanya call emergency untuk kawasaan Pantai Padang. Kemudian membiarkan Padang Baywatch melaku-kan patroli dan terjun kelaut untuk men-jaga keselamatan pengunjung sendirian, dengan safety mereka yang sangat minim dan beresiko. Begitu pula dengan Padang Baywatch masih lalai dalam menjaga dan merawat peralatan kese-lamatan yang dimilikinya, meletakkan perahu karet di tepi laut tampa alas pen-utup.

\section{PENUTUP}

Berdasarkan hasil pembahasan, diperoleh sebuah kesimpulan untuk menjawab rumusan masalah yang telah diajukan dalam penelitian ini adalah tentang budaya kerja sadar wisata yang responsif bagi keselamatan pengunjung (studi kolaborasi Pemerintah Kota Pada-ng dengan Padang Baywatch di Kawa-san Pantai Padang Kota Padang). Dalam hal ini, budaya kerja sadar wisata yang responsif bagi keselamatan pengunjung yang dilakukan Pemerintah Kota Padang yang berkolaborasi dengan Padang Bay-watch masih belum optimal. Terbukti masih banyaknya masalah-masalah me-ngenai budaya kerja sadar wisata pada petugas dari OPD terkait, yang mewakili Pemerintah Kota Padang maupun pada relawan Padang Baywatch. Seperti ma-sih lemahnya kemampuan Pemerintah Kota Padang bersama Padang Baywatch untuk melihat apa yang menjadi resiko disetiap bermain di pantai terbukti sa-rana keselamatan yang 
Sriwahyuni, Aldri FrinaldilBudaya Kerja Sadar Wista yang Responsif bagi Keselamatan Pengunjung (Studi Kolaborasi Pemerintah Kota Padang dengan Padang Baywatch di Kawasan Pantai Padang Kota Padang)

disediakan Pe-merintah maupun yang dimiliki Padang Baywatch sangat minim. Ditambah de-ngan menjaga keselamatan pengunjung hanya di lakukan pada eventevent ter-tentu saja. Lalu tidak semua dari pe-ngunjung yang mengetahui informasi keadaan lingkungan terkini yang disebabkan belum maksimalnya interaksi dan komunikasi yang dilakukan oleh Pemerintah Kota Padang maupun relawan Padang Baywatch. Kemudian, respon dalam menanggapi musibah yang di-alami pengunjung masih sangat lambat, selain petugas dan relawann hanya ada pada eventevent tertentu saja, tetapi ka-rena pada saat itu juga posko kese-lamatan hanya terpusat di Pantai Cim-pago. Dengan begitu, pemerintah Kota Padang juga masih lalai terhadap kewa-jibannya sebagai pemerintah derah un-tuk menjamin keselamatan pengunjung di derah wisata.

Oleh sebab itu Pemerintah Kota Pa-dang dalam hal ini diharapkan mampu memahami bahwa keselamatan pengunjung sangat penting dengan menetapkan konsep keselamatan pengunjung yang jelas yang tertuang dalam regulasi de-ngan menberdayagunakan potensi sear-ch and recue yang dimiliki relawan Pa-dang Baywatch.

\section{DAFTAR KEPUSTAKAAN}

Echols, J. M., \& Shadily, H. (2012). Kamus Inggris-Indonesia yang di Pernaharui. Jakarta: Gramedia.

Frinaldi, A. (2017). The Influence of Work Culture on Work Performance of Employees in Departement of Transportation, Communicatiton and Informatics of West Sumatera. Wahana Bhakti Praja, 7(2).

Frinaldi, A., \& Embi, M. A. (2014). Budaya Kerja Ewuh Pekewuh di Kalangan Pegawai Negeri Etnik Jawa (Studi Pada Kabupaten Pasaman Barat, Provinsi Sumatera Barat). Humanius, 13(1).
Frinaldi, A., \& Khaidir, A. (2017). Membangun Model Kebijakan Budaya Kerja Sadar Wisata di Kalangan Aparatur dan Masyrakat Pariwisata dalam Upaya Peningkatan Kepuasan Masyarakat Berkunjung ke Lokasi Wisata di Sumatera Barat. Padang: Lembaga Penelitian dan Pengabdian Masyarakat Universitas Negeri Padang.

Frinaldi, A., \& Khaidir, A. (2018). Membangun Model Kebijakan Budaya Kerja Sadar Wisata di Kalangan Aparatur dan Masyrakat Pariwisata dalam Upaya Peningkatan Kepuasan Masyarakat Berkunjung ke Lokasi Wisata di Sumatera. Padang: Lembaga Penelitian dan Pengabdian Masyarakat Universitas Negeri Padang.

Frinaldi, A., Khaidir, A., \& Yulista R, V. (2019). Policy Management to Develop Tourism Work Culture Consciousness and Increasing Viting People's Satisfaction. Studi Pemerintahan, 10(1).

Harini, S., \& Putra, R. I. (2017). Pengaruh Keselamatn Kerja (K3) terhadap Jumlah Penyakit Kerja dan Jumlah Kecelakaan Kerja Karyawan pada PT Hanei Indonesia. Visonida, 3(1).

Paramitha, F. (2012). Sarana Keselamatan Pengunjung Wisata Pantai (Studi Kasus Pantai Indah Ancol dan Pantai Jakat Bengkulu) Tahun 2011. Universitas Indonesia.

Rahayu, V. Y., Frinaldi, A., \& Khaidir, A. (2019). The Influence of Green Open Space adn Tourism-Counscious Work Culture On the Happiness of the People In Solok Regency. Universitas Negeri Padang. 
Sriwahyuni, Aldri Frinaldi/Budaya Kerja Sadar Wista yang Responsif bagi Keselamatan Pengunjung (Studi Kolaborasi Pemerintah Kota Padang dengan Padang Baywatch di Kawasan Pantai Padang Kota Padang)

Rahim, F. (2012). Buku Pedoman

Kelompok Sadar Wisata. Jakarta:

Direktur Jendral Pengembangan

Destinasi Pariwisata Kementrian

Pariwisata dan Ekonomi Kreatif.

Undang-undang Republik Indonesia Nomor 10 Tahun 2009 tentang

Kepariwisataan. (n.d.).

Undang-undang Republik Indonesia Nomor 23 Tahun 2014 tentang Pemerintah Daerah. (n.d.). 